\title{
Patient-specific template-guided versus standard freehand lumbar pedicle screw implantation: a randomized controlled trial
}

\author{
José Miguel Spirig, MD, ${ }^{1}$ Shayan Golshani, MMed, ${ }^{1,2}$ Nadja A. Farshad-Amacker, MD, ${ }^{3}$ and \\ Mazda Farshad, MD, MPH ${ }^{1}$ \\ ${ }^{1}$ Spine and ${ }^{3}$ Radiology Divisions, Balgrist University Hospital, University of Zurich; and ${ }^{2}$ Neurosurgical Division, Kantonsspital \\ Graubünden Hauptstandort, Switzerland
}

\begin{abstract}
OBJECTIVE Patient-specific template-guided (TG) pedicle screw placement currently achieves the highest reported accuracy in cadaveric and early clinical studies, with reports of reduced use of radiation and less surgical time. However, a clinical randomized controlled trial (RCT) eliminating potential biases is lacking. This study compares TG and standard freehand (FH) pedicle screw insertion techniques in an RCT.

METHODS Twenty-four patients (mean age 64 years, 9 men and 15 women) scheduled consecutively and independently from this study for 1-, 2-, or 3-level lumbar fusion were randomized to either the FH $(n=12)$ or TG $(n=12)$ group. Accuracy of pedicle screw placement, intraoperative parameters, and short-term complications were compared.

RESULTS A total of 112 screws ( $58 \mathrm{FH}$ and 54 TG screws) were implanted in the lumbar spine. Radiation exposure was significantly less in the TG group $\left(78.0 \pm 46.3 \mathrm{cGycm}^{2}\right)$ compared with the FH group $\left(234.1 \pm 138.1 \mathrm{cGycm}^{2}, \mathrm{p}=0.001\right)$. There were 4 pedicle screw perforations $(6.9 \%)$ in the FH group and $2(3.7 \%)$ in the TG group ( $p>0.99)$, with no clini$\mathrm{cal}$ consequences. Clinically relevant complications were 1 postoperative pedicle fracture in the $\mathrm{FH}$ group $(p>0.99), 1$ infection in the FH group, and 2 infections in the TG group $(p>0.99)$. There were no significant differences in surgical exposure time, screw insertion time, overall surgical time, or blood loss between the FH and TG groups.
\end{abstract}

CONCLUSIONS In this RCT, patient-specific TG pedicle screw insertion in the lumbar region achieved a high accuracy, but not better than a standardized FH technique. Even if intraoperative radiation exposure is less with the TG technique, the need for a preoperative CT scan counterbalances this advantage. However, more difficult trajectories might reveal potential benefits of the TG technique and need further research.

Clinical trial registration no.: NCT03318692 (clinicaltrials.gov)

https://thejns.org/doi/abs/10.3171/2020.10.SPINE201383

KEYWORDS patient-specific instrumentation; template-guided; pedicle screw; radiation dose; lumbar; surgical technique

$\mathrm{S}$ PINAL fusion by spinal instrumentation with pedicle screws is currently the standard technique in the treatment of many lumbar spine pathologies such as degenerative spinal disease, tumor, trauma, and spinal deformity. ${ }^{1-3}$ However, pedicle screw misplacement can have serious consequences, including neurological deficits. ${ }^{4,5}$ The accuracy of pedicle screw positioning varies from $49.7 \%$ to $91.7 \%$ with the conventional freehand $(\mathrm{FH})$ technique, depending on the surgeon's experience and the anatomical complexity. ${ }^{6,7}$ Several navigational techniques have been developed to improve the accuracy of pedicle screw positioning, including computer-assisted and robot- ic-assisted navigation. Computer-assisted navigation techniques have been reported to have an accuracy of 95\%$97 \% .^{8,9}$ The accuracy of robotic-assisted pedicle screw insertion varies from $93.4 \%$ to $98.7 \% .^{10-12}$ Templates used as patient-specific drill guides are a valuable alternative to the aforementioned navigational techniques. Since its first report in 1998 by Radermacher et al., ${ }^{13}$ this technique has been improved to an elegant and easily applicable navigational tool. Its accuracy (as high as 98\%), ${ }^{14}$ safety, time efficiency, and low demand for radiation exposure and surgeon experience have been reported in several retrospective clinical and cadaveric studies. ${ }^{14-22}$ However, to our

ABBREVIATIONS CBT = cortical bone trajectory; $\mathrm{FH}=$ freehand; $\mathrm{RCT}=$ randomized controlled trial; $\mathrm{TG}$ = template-guided.

SUBMITTED July 26, 2020. ACCEPTED October 22, 2020.

INCLUDE WHEN CITING Published online May 28, 2021; DOI: 10.3171/2020.10.SPINE201383. 


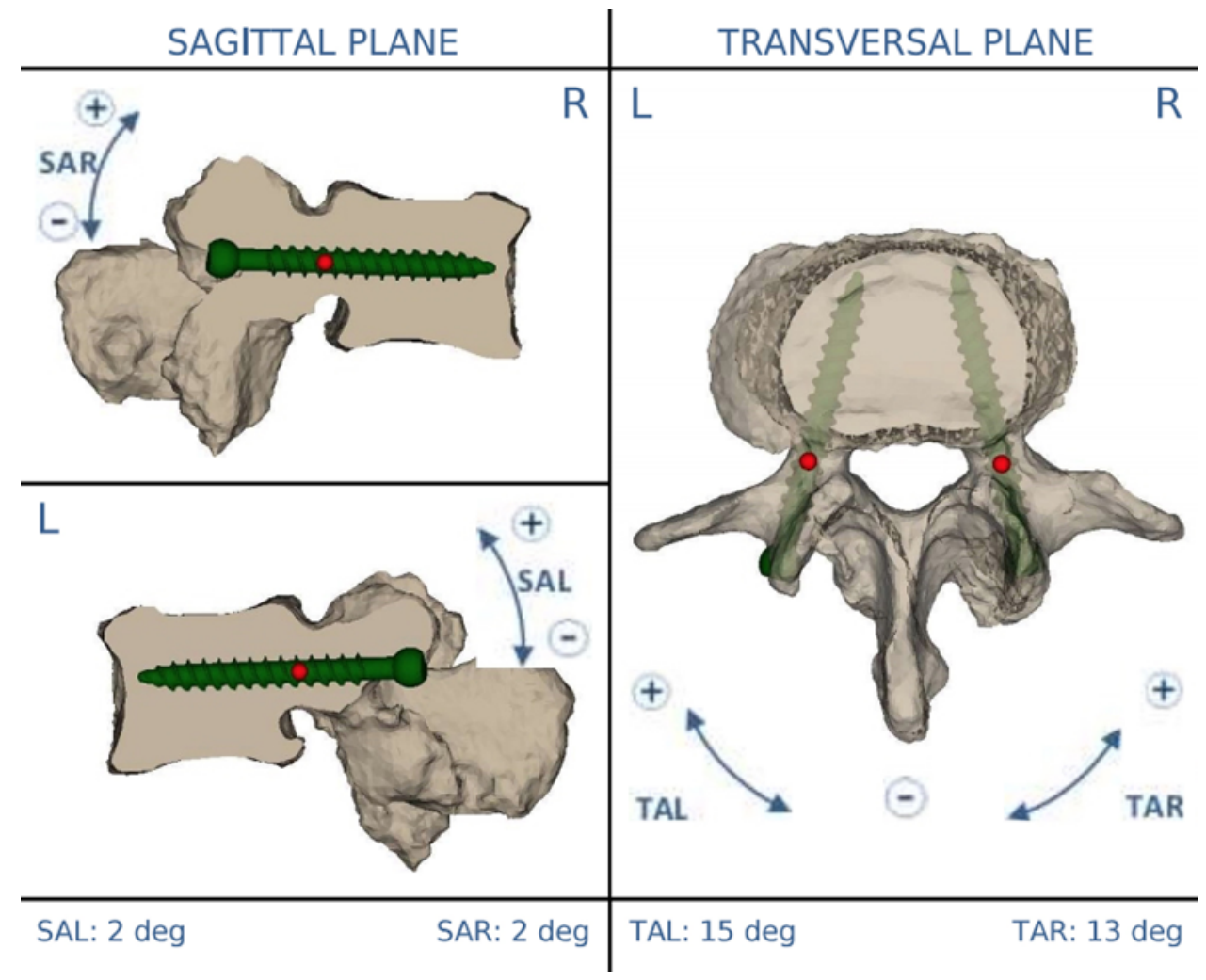

FIG. 1. Surgical plan of the screw trajectory for the L5 vertebra (Medacta MySpine web platform). SAL/SAR = sagittal plane angle left/right of the screw shaft in relation to the pedicle center line; TAL/TAR = transverse plane angle left/right of the screw shaft in relation to the pedicle center line. Figure is available in color online only.

knowledge, there is still no clinical randomized controlled trial (RCT) evaluating this technique in comparison to the standard FH technique. The FH technique is the gold standard at our institution. It incorporates fluoroscopic guidance at the discretion of the surgeon depending on his or her need and experience. We therefore aimed to prospectively compare the patient-specific template-guided (TG) technique with the $\mathrm{FH}$ technique in a randomized clinical setting, thus reducing the potential of biases to a minimum by the chosen study design methodology.

\section{Methods}

The present study was approved by the Cantonal Ethics Committee on research involving humans (clinical trial registration no. NCT03318692; clinicaltrials.gov) and conducted at Balgrist University Hospital. Every patient involved in this study provided written informed consent before inclusion.

\section{Patients}

Patients older than 18 years, who were scheduled for 1-, 2-, or 3-level lumbar fusion surgery independent from this trial, were identified between June 2017 and December 2018 (18 months). Indications for surgery were degenerative spinal pathologies such as degenerative spondylolisthesis, segmental instability, foraminal stenosis, and refractory lumbar back pain caused by an isolated degen- erative disc disease. Exclusion criteria were previous lumbar surgeries, indication for more than 3-level fusion, and surgical emergencies.

These patients were asked to participate in the RCT and, upon recruitment, were randomized to either the FH or TG pedicle screw insertion group. All patients received a preoperative CT scan of the lumbar spine, if not already available. A specific low-dose CT protocol (99. MYS.1P_CT Rev.03) designed by the Medacta Company was used to reduce radiation exposure. In the TG group, the CT data set was sent to the MySpine Medacta web platform (https://myspine.medacta.com) to develop a digital screw trajectory plan for each vertebra (Fig. 1). After confirmation of the screw parameters (length, diameter, and trajectory) by the surgeon, specific 3D vertebra models and corresponding guides were designed and printed. The "MySpine" template guides and vertebra models are made of polyamide-PA12 (Fig. 2); they were sterilized in a standardized manner for surgery.

\section{Surgical Procedure}

All surgeries were performed by at least one or two experienced surgeons (J.M.S. and M.F.). Exposure of the spine was conducted as usual with special depiction of the bone surface in the laminar, isthmic, and transverse process regions in all patients. For the TG group, a highspeed drill with a $2.7-\mathrm{mm}$ drill bit was used after position- 


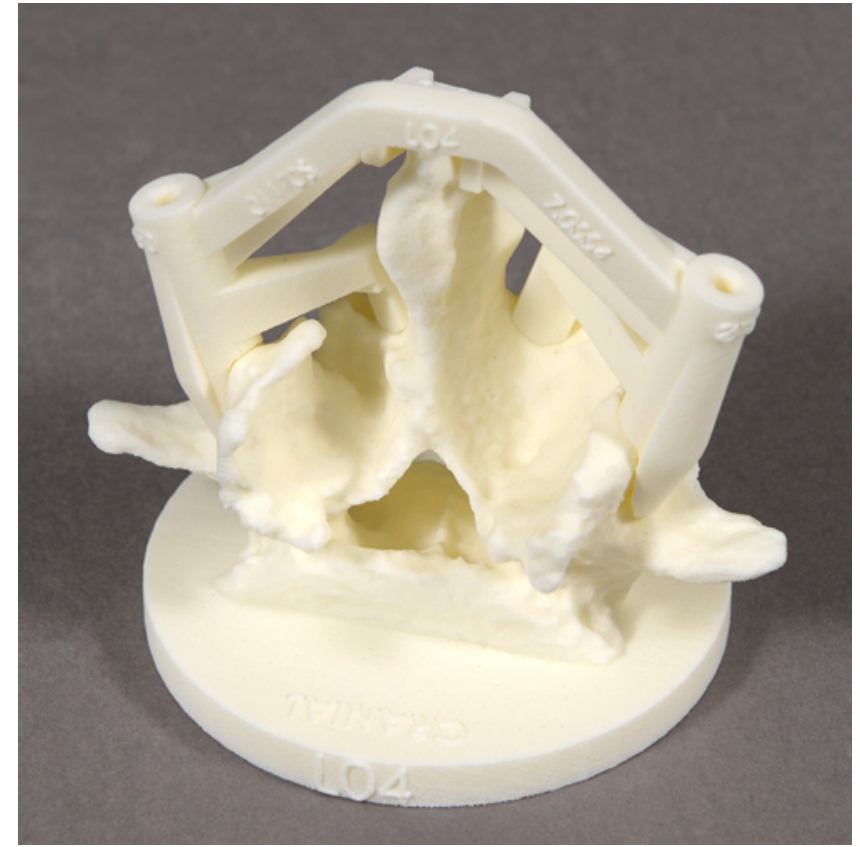

FIG. 2. 3D-printed patient-specific template guide with vertebra model. Figure is available in color online only.

ing the drill guides on the vertebra. A predefined depth stopper was used according to the planned screw length. The drill guides were removed after placing a K-wire in the drill hole to guide the cannulated screws. The K-wire was removed after placing the screw. Finally, intraoperative fluoroscopy was used to check for adequate screw positioning. The surgeon was free to reposition a screw in cases of detected screw malpositioning on radiographs.

For the standard FH technique, the entry point was identified and prepared according to the anatomical landmarks. The pedicle was then perforated with a Lenke bone probe under lateral fluoroscopic control. A small ball tip was used to check bone integrity of the surrounding pedicle walls. Finally, a screw was inserted FH.

The time needed for surgical exposure and screw insertion, as well as overall surgical time, was recorded. Exposure time started with the skin incision and ended if the use of electrocautery was terminated after identifying the screw entry point. Subsequently, the screw insertion time started and ended after fluoroscopic control of the last screw. The screw insertion time was normalized by dividing the total time by the number of screws inserted. The overall surgical time lasted from skin incision until finished skin closure. Other measured intraoperative parameters were overall blood loss and intraoperative radiation dose.

\section{Postoperative Radiological Assessment}

An immediate postoperative CT scan was performed (Fig. 3) in both groups to assess the accuracy of pedicle screws. All CT images were acquired in the axial plane using a 64-MDCT scanner (Brilliance CT, Philips Healthcare), with tube voltage of $120 \mathrm{kV}$, tube current of $200 \mathrm{~mA}$, slice thickness of $1 \mathrm{~mm}$, and matrix of $512 \times 512$. Coro-

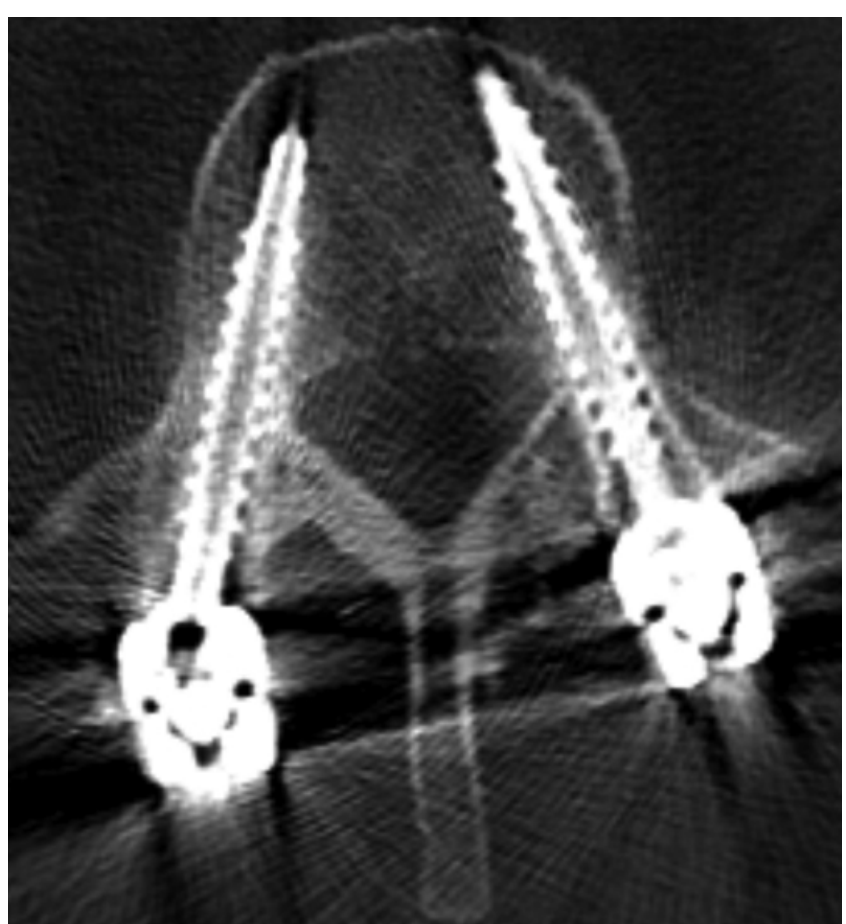

FIG. 3. Postoperative axial CT scan for assessment of accuracy.

nal and sagittal images were secondarily reconstructed. The accuracy on the CT was assessed by an independent radiologist (N.A.F.A.), blinded to the performed surgical technique of pedicle screw insertion. Pedicle wall perforation was graded according to the Gertzbein classification ${ }^{23}$ using a $2-\mathrm{mm}$ increment scale, as also recommended. ${ }^{24}$

\section{Complication Monitoring}

Finally, the type and amount of complications occurring perioperatively and within at least 3 months were recorded and compared between the groups.

\section{Statistical Analysis}

Descriptive statistics were used to report means, standard deviations, and ranges. Interval scaled outcomes were compared between the treatment groups with independent-sample t-tests with unequal variance correction as applicable. Frequencies were compared using Fisher's exact tests. Statistical analysis was conducted using IBM SPSS (version 26.0, IBM Corp.). A p value $<0.05$ was considered statistically significant.

\section{Results}

This RCT was interrupted at 24 patients enrolled as the superiority of the TG technique was not sufficiently clinically relevant to justify continuation of the RCT. Thirtysix patients scheduled for lumbar fusion surgery were initially assessed for eligibility: 10 patients declined to participate, and 2 did not have sufficient local language skills to give informed consent. Ultimately, 24 patients provided informed consent for randomization to either the standard FH $(n=12)$ or TG $(n=12)$ pedicle screw insertion group 


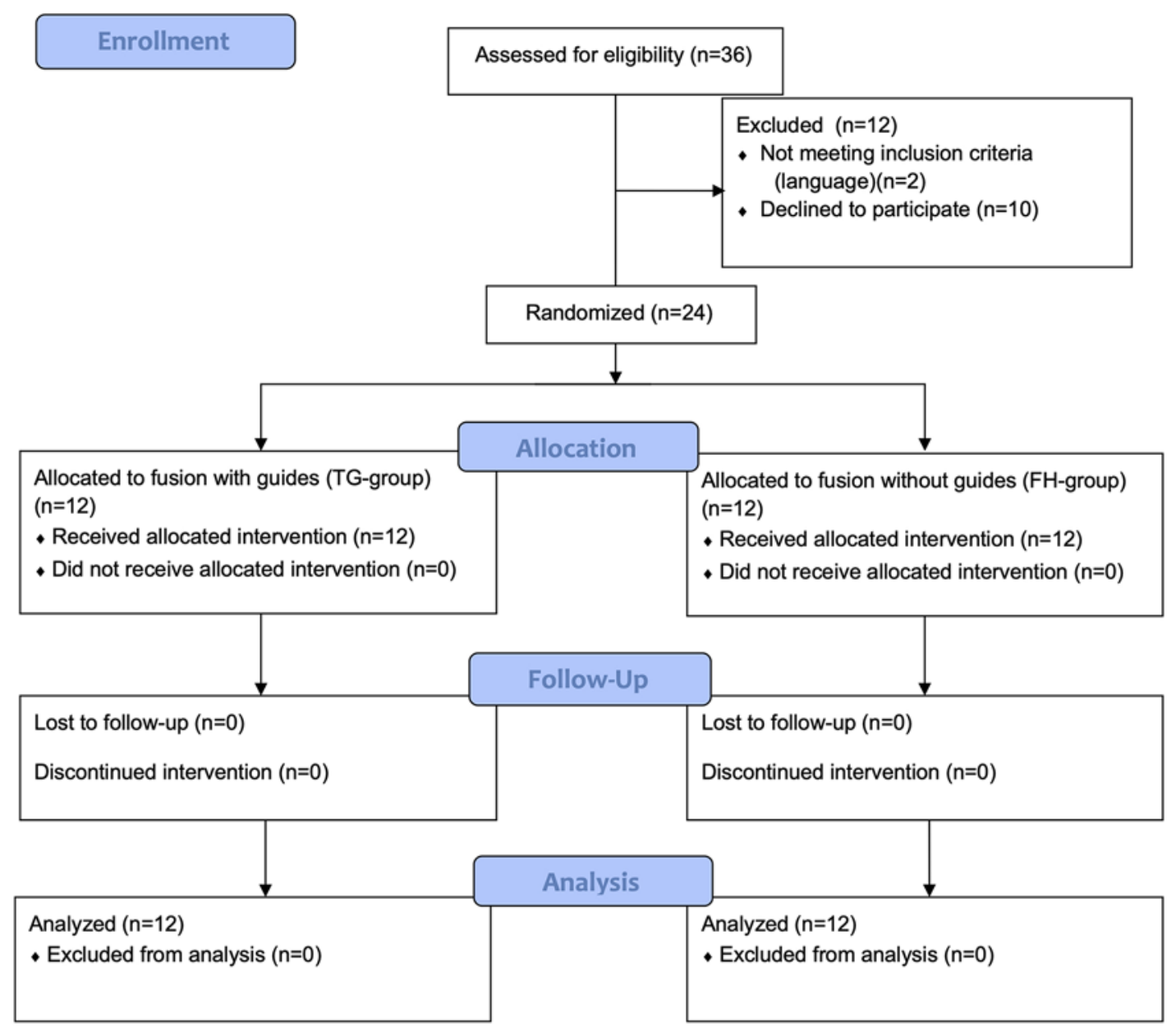

FIG. 4. Enrollment flow diagram. Figure is available in color online only.

in a blinded fashion (Fig. 4). The demographics and characteristics of those 24 included patients are summarized in Table 1.

A total of 112 screws (58 FH screws and 54 TG screws) were implanted. Nine single-level instrumentations and fusions were performed in both groups. Most $(\mathrm{n}=16)$ were performed at L4-5 $(n=8)$ and L5-S1 $(n=8)$, whereas L3-4 was instrumented only twice (Table 2).

No screw reinsertion was performed after intraoperative fluoroscopic control imaging. There were no significant differences in surgical exposure time, screw insertion time, screw insertion time per screw, overall surgical time,

TABLE 1. Patient characteristics $(n=24)$

\begin{tabular}{lccc}
\hline \multicolumn{1}{c}{ Variable } & FH Group & TG Group & All \\
\hline Mean age \pm SD, yrs & $65 \pm 12.8$ & $63 \pm 15.1$ & $64 \pm 15.1$ \\
\hline Sex & & & \\
\hline Women & 8 & 7 & 15 \\
\hline Men & 4 & 5 & 9 \\
\hline Mean BMl $\pm \mathrm{SD}, \mathrm{kg} / \mathrm{m}^{2}$ & $29.5 \pm 5.5$ & $27.1 \pm 4.7$ & $28.3 \pm 4.7$ \\
\hline
\end{tabular}

Differences between groups were not statistically significant. and blood loss between the FH and TG groups (Table $3)$. However, radiation exposure was significantly less in the TG group, with $78.0 \pm 46.3 \mathrm{cGycm}^{2}$ vs $234.1 \pm 138.1$ $\mathrm{cGycm}^{2}$ in the FH group $(\mathrm{p}=0.001)$. Two paravertebral skin stab incisions to pass the drill through had to be completed in two TG surgeries at L5, due to the inability to

TABLE 2. Instrumented levels per group

\begin{tabular}{lccc}
\hline Fused Levels & FH Group & TG Group & Total \\
\hline L3-4 & 0 & 2 & 2 \\
\hline L4-5 & 5 & 3 & 8 \\
\hline L5-S1 & 4 & 4 & 8 \\
\hline L3-5 & 0 & 3 & 3 \\
\hline L4-S1 & 1 & 0 & 1 \\
\hline L3-S1 & 1 & 0 & 1 \\
\hline T12-L1 \& L3-4 & 1 & 0 & 1 \\
\hline Total & 12 & 12 & 24 \\
\hline 1-level fusion & 9 & 9 & 18 \\
\hline 2-level fusion & 2 & 3 & 5 \\
\hline 3-level fusion & 1 & 0 & 1 \\
\hline
\end{tabular}


TABLE 3. Surgical parameters per group

\begin{tabular}{lccc}
\hline \multicolumn{1}{c}{ Parameter } & FH Group & TG Group & p Value \\
\hline Surgical exposure time (mins) & $32.4 \pm 8.8$ & $39.2 \pm 12.6$ & 0.172 \\
\hline $\begin{array}{l}\text { Screw insertion time per } \\
\text { patient (mins) }\end{array}$ & $27.2 \pm 11.6$ & $32.8 \pm 13.1$ & 0.314 \\
\hline $\begin{array}{l}\text { Screw insertion time per } \\
\text { screw (mins) }\end{array}$ & $5.5 \pm 1.6$ & $7.5 \pm 3.5$ & 0.100 \\
\hline Overall surgical time (mins) & $157.6 \pm 34.2$ & $176.3 \pm 35.1$ & 0.201 \\
\hline Blood loss (ml) & $366.7 \pm 189.9$ & $491.6 \pm 350.9$ & 0.290 \\
\hline Radiation exposure (cGycm ${ }^{2}$ ) & $234.1 \pm 138.1$ & $78.0 \pm 46.3$ & 0.001 \\
\hline
\end{tabular}

Boldface type indicates statistical significance.

otherwise maintain the drill trajectory because of the soft tissue pushing the drill medially.

\section{Accuracy of Pedicle Screw Insertion}

The postoperative $\mathrm{CT}$ revealed 4 pedicle screw perforations $(6.9 \%)$ in the FH group and 2 (3.7\%) in the TG group $(\mathrm{p}>0.99)$. All perforations in the FH group were medial, whereas in the TG group 1 perforation was lateral and 1 was medial. All perforations were less than $2 \mathrm{~mm}$ and had no clinical consequences (Fig. 5).

\section{Complications}

Clinically relevant complications were 1 postoperative pedicle fracture in the FH group ( $p>0.99), 1$ infection in the FH group, and 2 infections in the TG group ( $>0.99)$.

\section{Discussion}

This is the first RCT comparing the standard radiographically controlled FH technique to the patient-specific TG pedicle screw insertion technique. It could be documented that both techniques had an accuracy of $100 \%$ of screws inserted within the safe zone of a 2-mm breach; 93.1\% (FH) and 96.3\% (TG) of screws were placed completely within the pedicle. The latter value is concordant with the previously published accuracy rate of $97.92 \%$ with the TG technique in currently the only randomized cadaver study by Farshad et al. ${ }^{14}$ Similar accuracies ranging from $96.1 \%$ to $100 \%$ were reported for the TG technique in other nonrandomized studies. ${ }^{15,17,20-22,25,26}$ However, the accuracy of the FH technique in our study far exceeds the $81.25 \%$ rate published in the randomized cadaver study by Farshad et al. ${ }^{14}$ The reason for this discrepancy might be that no screws were inserted in the thoracic region, whereas most of the pedicle breaches were reported to be within the thoracic spine in their study. ${ }^{14}$ Other studies report accuracies of the $\mathrm{FH}$ technique as low as $49.7 \%{ }^{6,7}$ We believe that the relatively high accuracy of the FH technique reported here is due to the experience levels of the surgeons in a high-volume university spine center with more than 1000 surgical cases per year, as surgical experience is known to have a positive correlation with the accuracy of the FH technique. ${ }^{27-29}$ This is not yet clear for the TG technique; Farshad et al., ${ }^{14}$ for example, could not show any influence of experience level on the grade of pedicle perforation using the TG technique. Nonetheless, it must be emphasized

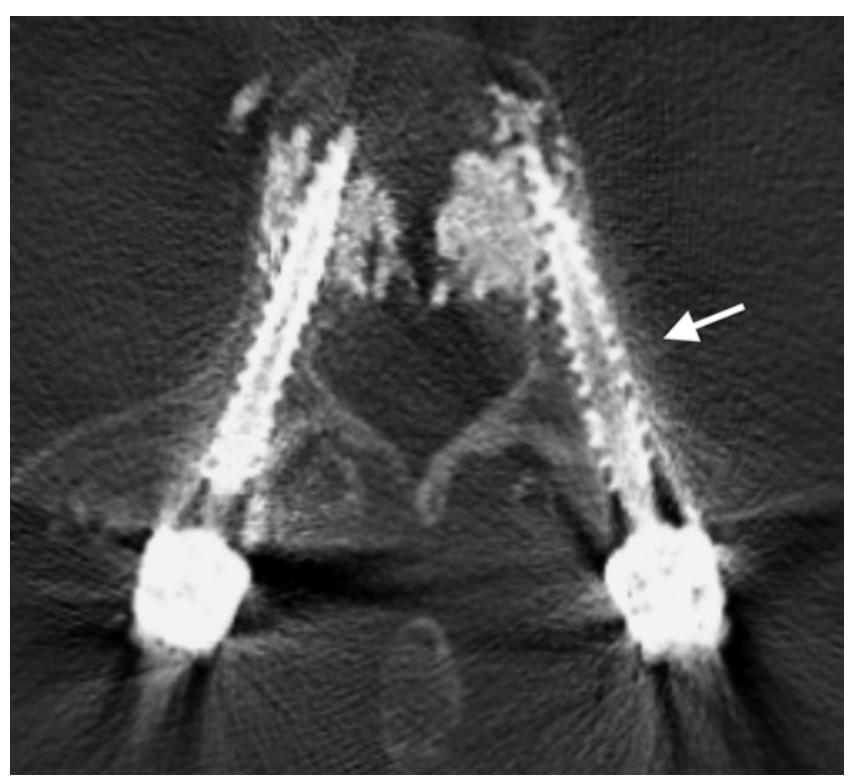

FIG. 5. Postoperative axial CT scan (TG group) showing lateral pedicle screw perforation (arrow) on the left side.

that this was not their first study aim, and they compared only one board-certified versus one senior-level resident.

Another important finding in our study was that the intraoperative radiation exposure could be significantly reduced from 234 to $78 \mathrm{cGycm}^{2}$ by using the TG technique. The latter value represents the final intraoperative fluoroscopic use, which includes an anteroposterior view, two oblique views, and one lateral view. This is the standard minimum radiation exposure in our clinic to ensure pedicle screw accuracy. The TG technique minimizes radiation exposure to the surgical team, and in particular to the surgeon. This might be an advantage, considering the large amount of radiation exposure to a spine surgeon during the span of his or her career. However, even if the surgical team and the patient might be exposed to a reduced intraoperative radiation dose, the absolute need of a preoperative CT scan for the production of the templates counterbalances this advantage for the patient. Current research is targeting the use of MRI for digital segmentation of vertebral anatomy.

We report a tendency for a longer surgical time and greater blood loss in the TG group. This might reflect the subjectively experienced need for larger wound exposure and meticulous removal of soft tissue from bone contact points for proper guide fitting in the TG group. Especially for pedicle screws at L4 and L5, we experienced some difficulty maintaining the adequate drill trajectory due to the voluminous soft tissue pushing the drill medially and thereby dislocating the drill guide. For this reason, 2 patients needed two additional paravertebral skin stab incisions at L5 in this trial. Therefore, it can be stated that the TG technique for traditional pedicle screw trajectories cannot be performed through a minimally invasive approach. However, a divergent screw trajectory, such as that performed with the cortical bone trajectory (CBT) technique, allows benefits from TG technology and also 
permits minimal invasiveness. ${ }^{30-33}$ The size of the skin incision is reported to be approximately $5 \mathrm{~cm}$ for a singlelevel instrumentation, and the transverse processes do not have to be exposed. ${ }^{32}$ Current research at our institution compares the differences of a standard trajectory to CBT within another RCT.

One limitation of the TG technique is its reduced accuracy in cases of spondylolysis, in which the lamina can be floating to a certain amount due to its dissociation from the vertebral body and pedicles. A firm and important foothold for the guide is therefore lacking in these cases. Patients with spondylolysis were therefore excluded from our study. The same principle applies to patients with spina bifida or previous laminectomies. However, no other anatomical features, and specifically no degenerative changes of the anatomy, were found to be obstacles for guide application and therefore a reason for exclusion of patients in our study.

As with any navigational technique, the TG technique has its additional costs for planning, production, and sterilization of the guides compared with the $\mathrm{FH}$ technique. The costs might differ depending on country, producing company, actual demand, and commercial agreement. Medacta states that as a rule of thumb, the costs per guide for 1 vertebra equal the price for 1 pedicle screw. A costeffectiveness study is needed to illuminate a potential balance between surgical cost and potential reduction of costs created by lesser rates of complications.

One limitation of this study is its small sample size. The difference between the FH and TG techniques could become more apparent in regard to accuracy, blood loss, and surgical time needed if more patients had been included. We felt, however, that such a difference would be too small and would require too high a number to treat to be clinically relevant. Therefore, this RCT was interrupted after enrolling just 24 patients instead of 60 , as superiority of the TG was not sufficiently clinically relevant to justify continuation of the RCT. Instead, the TG was modified to the CBT and another RCT arm was created and is the subject of current research. Another limitation is the short follow-up duration, obviating statements about fusion rates and patient outcome. However, this was not the subject of the study, as we aimed to primarily compare the surgical differences of both surgical techniques.

\section{Conclusions}

With this RCT, we conclude that patient-specific TG pedicle screw insertion in the lumbar region achieves a high accuracy, but not better than a standardized FH technique in experienced hands. While significant reduction in intraoperative radiation exposure occurs for the surgeon with the TG technique, the patient is exposed to the radiation caused by a preoperative CT scan. Therefore, the TG technique for standard trajectories of pedicle screws does not appear to bring any clinically relevant advantages. Other trajectories might reveal potential benefits of TG instrumentation and need further research.

\section{References}

1. Boos N, Webb JK. Pedicle screw fixation in spinal disorders: a European view. Eur Spine J. 1997;6(1):2-18.
2. Gaines RW Jr. The use of pedicle-screw internal fixation for the operative treatment of spinal disorders. J Bone Joint Surg Am. 2000;82(10):1458-1476.

3. Rajaee SS, Bae HW, Kanim LEA, Delamarter RB. Spinal fusion in the United States: analysis of trends from 1998 to 2008. Spine (Phila Pa 1976). 2012;37(1):67-76.

4. Gautschi OP, Schatlo B, Schaller K, Tessitore E. Clinically relevant complications related to pedicle screw placement in thoracolumbar surgery and their management: a literature review of 35,630 pedicle screws. Neurosurg Focus. 2011; 31(4):E8.

5. Parker SL, Amin AG, Santiago-Dieppa D, et al. Incidence and clinical significance of vascular encroachment resulting from freehand placement of pedicle screws in the thoracic and lumbar spine: analysis of 6816 consecutive screws. Spine (Phila Pa 1976). 2014;39(8):683-687.

6. Mason A, Paulsen R, Babuska JM, et al. The accuracy of pedicle screw placement using intraoperative image guidance systems. J Neurosurg Spine. 2014;20(2):196-203.

7. Gelalis ID, Paschos NK, Pakos EE, et al. Accuracy of pedicle screw placement: a systematic review of prospective in vivo studies comparing free hand, fluoroscopy guidance and navigation techniques. Eur Spine J. 2012;21(2):247-255.

8. Ughwanogho E, Patel NM, Baldwin KD, et al. Computed tomography-guided navigation of thoracic pedicle screws for adolescent idiopathic scoliosis results in more accurate placement and less screw removal. Spine (Phila Pa 1976). 2012; 37(8):E473-E478.

9. Meng XT, Guan XF, Zhang HL, He SS. Computer navigation versus fluoroscopy-guided navigation for thoracic pedicle screw placement: a meta-analysis. Neurosurg Rev. 2016;39(3): 385-391.

10. Han X, Tian W, Liu Y, et al. Safety and accuracy of robotassisted versus fluoroscopy-assisted pedicle screw insertion in thoracolumbar spinal surgery: a prospective randomized controlled trial. J Neurosurg Spine. 2019;30(5):615-622.

11. Benech CA, Perez R, Benech F, et al. Navigated robotic assistance results in improved screw accuracy and positive clinical outcomes: an evaluation of the first 54 cases. J Robot Surg. 2020;14(3):431-437.

12. Molliqaj G, Schatlo B, Alaid A, et al. Accuracy of robotguided versus freehand fluoroscopy-assisted pedicle screw insertion in thoracolumbar spinal surgery. Neurosurg Focus. 2017;42(5):E14

13. Radermacher K, Portheine F, Anton M, et al. Computer assisted orthopaedic surgery with image based individual templates. Clin Orthop Relat Res. 1998;354(354):28-38.

14. Farshad M, Betz M, Farshad-Amacker NA, Moser M. Accuracy of patient-specific template-guided vs. free-hand fluoroscopically controlled pedicle screw placement in the thoracic and lumbar spine: a randomized cadaveric study. Eur Spine J. 2017;26(3):738-749.

15. Lamartina $C$, Cecchinato $R$, Fekete Z, et al. Pedicle screw placement accuracy in thoracic and lumbar spinal surgery with a patient-matched targeting guide: a cadaveric study. Eur Spine J. 2015;24(suppl 7):937-941.

16. Putzier M, Strube P, Cecchinato R, et al. A new navigational tool for pedicle screw placement in patients with severe scoliosis: a pilot study to prove feasibility, accuracy, and identify operative challenges. Clin Spine Surg. 2017;30:E430-E439.

17. Ma T, Xu YQ, Cheng YB, et al. A novel computer-assisted drill guide template for thoracic pedicle screw placement: a cadaveric study. Arch Orthop Trauma Surg. 2012;132(1): 65-72.

18. Wu ZX, Huang LY, Sang HX, et al. Accuracy and safety assessment of pedicle screw placement using the rapid prototyping technique in severe congenital scoliosis. J Spinal Disord Tech. 2011;24(7):444-450.

19. Liu K, Zhang Q, Li X, et al. Preliminary application of a 
multi-level 3D printing drill guide template for pedicle screw placement in severe and rigid scoliosis. Eur Spine J. 2017; 26(6):1684-1689.

20. Lu S, Xu YQ, Zhang YZ, et al. A novel computer-assisted drill guide template for lumbar pedicle screw placement: a cadaveric and clinical study. Int J Med Robot. 2009;5(2): 184-191.

21. Sugawara T, Higashiyama N, Kaneyama S, et al. Multistep pedicle screw insertion procedure with patient-specific lamina fit-and-lock templates for the thoracic spine: clinical article. J Neurosurg Spine. 2013;19(2):185-190.

22. Hu Y, Yuan ZS, Spiker WR, et al. A comparative study on the accuracy of pedicle screw placement assisted by personalized rapid prototyping template between pre- and post-operation in patients with relatively normal mid-upper thoracic spine. Eur Spine J. 2016;25(6):1706-1715.

23. Gertzbein SD, Robbins SE. Accuracy of pedicular screw placement in vivo. Spine (Phila Pa 1976). 1990;15(1):11-14.

24. Aoude AA, Fortin M, Figueiredo R, et al. Methods to determine pedicle screw placement accuracy in spine surgery: a systematic review. Eur Spine J. 2015;24(5):990-1004.

25. Lu S, Zhang YZ, Wang Z, et al. Accuracy and efficacy of thoracic pedicle screws in scoliosis with patient-specific drill template. Med Biol Eng Comput. 2012;50(7):751-758.

26. Merc M, Drstvensek I, Vogrin M, et al. A multi-level rapid prototyping drill guide template reduces the perforation risk of pedicle screw placement in the lumbar and sacral spine. Arch Orthop Trauma Surg. 2013;133(7):893-899.

27. Park SM, Shen F, Kim HJ, et al. How many screws are necessary to be considered an experienced surgeon for freehand placement of thoracolumbar pedicle screws?: analysis using the cumulative summation test for learning curve. World Neurosurg. 2018;118:e550-e556.

28. Gonzalvo A, Fitt G, Liew S, et al. The learning curve of pedicle screw placement: how many screws are enough? Spine (Phila Pa 1976). 2009;34(21):E761-E765.

29. Gang C, Haibo L, Fancai L, et al. Learning curve of thoracic pedicle screw placement using the free-hand technique in scoliosis: how many screws needed for an apprentice? Eur Spine J. 2012;21(6):1151-1156.
30. Matsukawa K, Kaito T, Abe Y. Accuracy of cortical bone trajectory screw placement using patient-specific template guide system. Neurosurg Rev. 2020;43(4):1135-1142.

31. Kaito T, Matsukawa K, Abe Y, et al. Cortical pedicle screw placement in lumbar spinal surgery with a patient-matched targeting guide: a cadaveric study. J Orthop Sci. 2018;23(6): $865-869$.

32. Marengo N, Matsukawa K, Monticelli M, et al. Cortical bone trajectory screw placement accuracy with a patient-matched 3-dimensional printed guide in lumbar spinal surgery: a clinical study. World Neurosurg. 2019;130:e98-e104.

33. Kim J, Rajadurai J, Choy WJ, et al. Three-dimensional patient-specific guides for intraoperative navigation for cortical screw trajectory pedicle fixation. World Neurosurg. 2019;122: $674-679$.

\section{Disclosures}

The Medacta Company financed postoperative CT, patient-specific guide planning, and guide production. Medacta had no role in the study design, data collection and analysis, decision to publish, or preparation of the manuscript.

\section{Author Contributions}

Conception and design: Spirig, Golshani, Farshad. Acquisition of data: Spirig, Farshad-Amacker. Analysis and interpretation of data: Spirig, Farshad. Drafting the article: Spirig, Golshani. Critically revising the article: all authors. Reviewed submitted version of manuscript: Spirig, Farshad. Approved the final version of the manuscript on behalf of all authors: Spirig. Statistical analysis: Spirig. Administrative/technical/material support: Spirig, Golshani, Farshad. Study supervision: Spirig, Farshad.

\section{Correspondence}

José Miguel Spirig: Balgrist University Hospital, Zurich, Switzerland.jose.spirig@balgrist.ch. 